\title{
A 100 años del Parque José Domingo Gómez Rojas: su restauración o su muerte
}

M. I sabel Pavez Reyes

\section{Resumen}

Al cumplirse 100 años del Parque J.D.Gómez Rojas, se argumenta las razones para su restauración en la perspectiva del Bicentenario de la Independencia de Chile.

Palabras claves: PARQUE JOSÉ DOMINGO GÓMEZ ROJAS DE SANTIAGO DE CHILE. CORREDOR ECOLÓGICO DEL RÍO MAPOCHO.

\author{
Abstract \\ Indice \\ Introducción \\ Cinco aclaraciones \\ Acciones negativas \\ Conclusiones \\ Bibliografía
}

In the perspective of the Chile Bicentennial, the author points out the reasons for the restoration project of the hundred-year-old J.D. Gómez Rojas Park.

\section{Introducción}

El Parque José Domingo Gómez Rojas ha cumplido 100 años desde su instauración en la ladera norte del río Mapocho, conformando un par con el Parque Forestal (19062006), ambos proyectos creados en la perspectiva del Centenario de la Independencia de Chile.

Este proyecto - del Arqto. Pedro E. Wieland, jefe de la Oficina del Plan de Santiago, c. 1905- tiene su orígen en la propuesta del segundo plan de ordenamiento y transformación de Santiago, y corresponde su formulación a la iniciativa de Alejandro Bertrand (1900-1906). Posteriormente, Alberto Mackenna Subercaseaux realzó esta proposición cuando formuló la necesidad de crear vías costaneras del río Mapocho a cuya vera debían mantenerse los parques existentes e incrementarse a todo lo largo del río ${ }^{1}$.

El parque ya se observa muy frondoso en las fotografías del primer cuarto del siglo XX, cuando su nombre era "Campos de Sport" y se encontraba plantado entre el puente Pío Nono y Purísima, esto es, en la mitad de su superficie ${ }^{2}$.

El nombre que hoy tiene le fue colocado en homenaje al poeta, estudiante de Derecho y de Pedagogía, José Domingo Gómez Rojas (1896-1920) hacia los años 1940³. Gómez Rojas fue uno de los líderes de un vigoroso movimiento estudiantil de los años 1920

\footnotetext{
${ }^{1}$ Entrevista al Arqto. Alberto Gurovich W., académico del D. Urbanismo, F.A.U. Universidad de Chile, junio de 2007.

2 BOLOÑA, Nicanor (Cartógrafo), s/f. "Plano jeneral de la ciudad de Santiago e inmediaciones", escala original 1:8.500, 4a edición.

${ }^{3}$ ALBURQUERQUE FUSCHINI, Germán, 1999. "Gómez Rojas, el Cristo de los poetas". En: REVISTA DERECHO Y HUMANIDADES №7, Facultad de Derecho de la Universidad de Chile, pp. 153-168. [Capítulo de tesis para optar a Licenciatura en Historia, P. U. Católica de Chile, 1997].
} 
que el Gobierno de Sanfuentes ordenó reprimir. En esas circunstancias Gómez Rojas fue detenido, enfermando gravemente de meningitis y falleciendo a la edad de 24 años ${ }^{4}$.

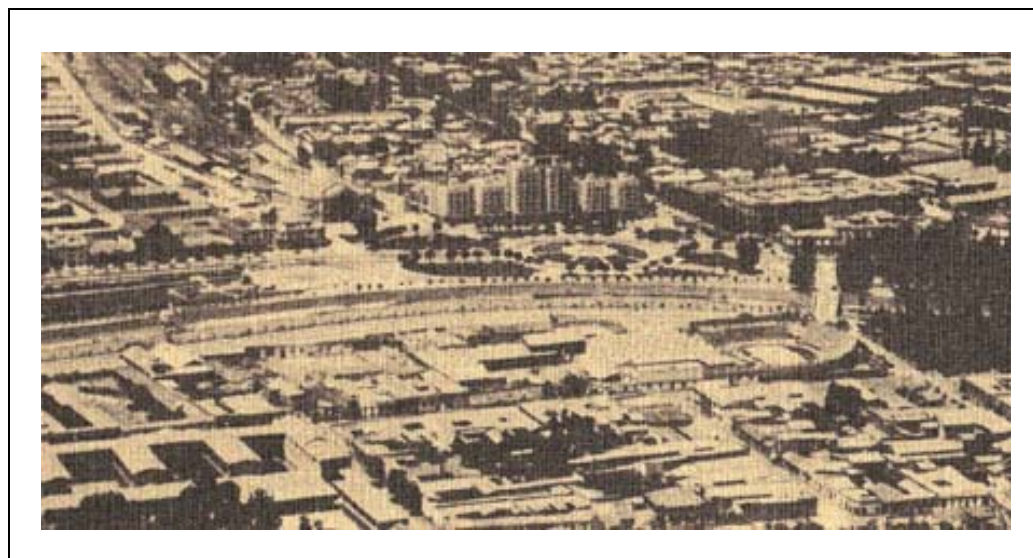

Fig.1. Acometida del Parque Gómez Rojas en calle Pío Nono, c. 1929 (a la derecha de la fotografía).

Fte.: Sección de fotografía en: LEHMANN DE IZQUIERDO, Antonia y MÉNDEZ B., Ramón Alfonso. La ciudad y sus arquitectos. Concurso de Anteproyectos Plaza Baquedano, Santiago de Chile, Ed. Universitaria S.A., 1982, 76 págs.

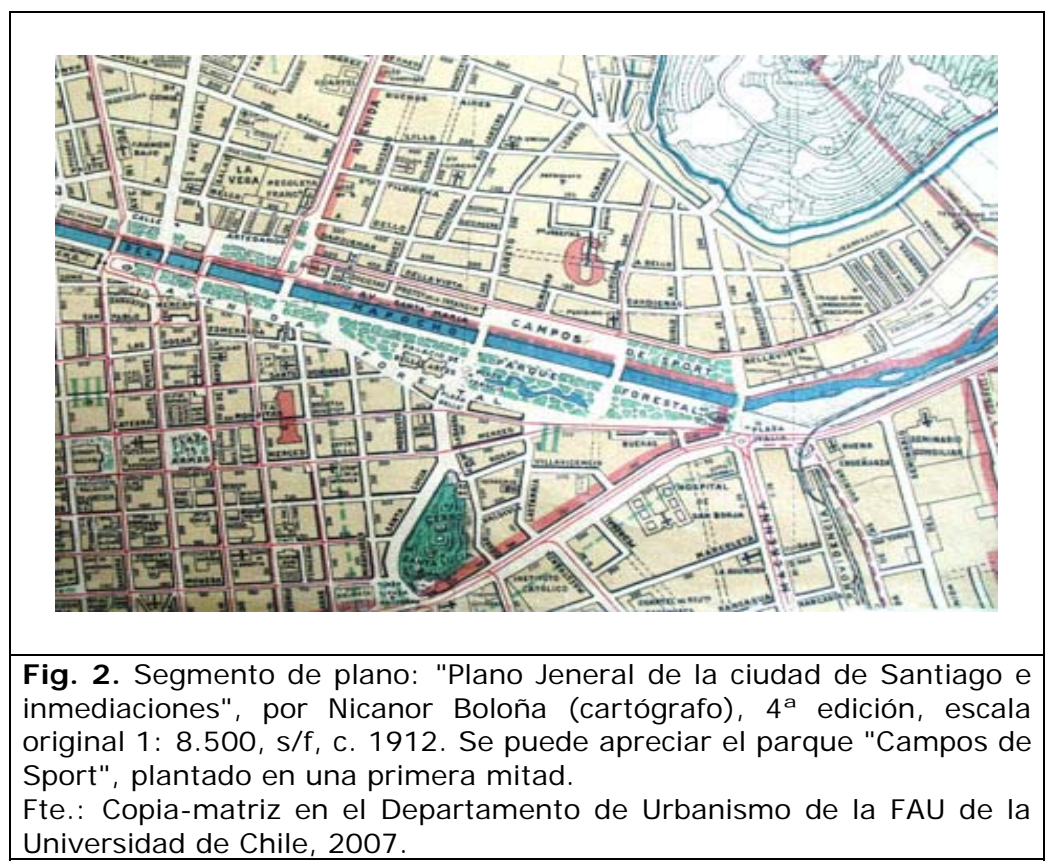

${ }^{4}$ Idem. 


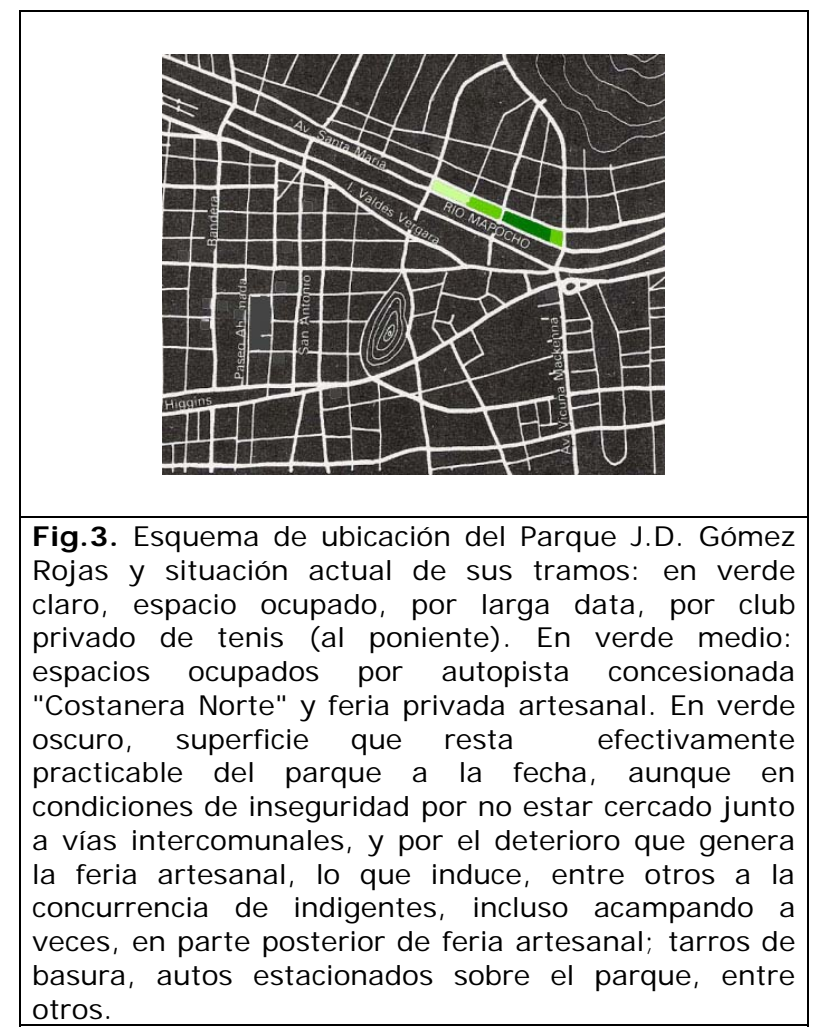

\section{Cinco aclaraciones}

Frente a la noticia aparecida en la prensa el día 17 de junio de $2007^{5}$, respecto de un megaproyecto residencial en Pío Nono con Bellavista, más otras intervenciones en el área incluyendo una acción sobre "los terrenos de la feria artesanal" en necesario esclarecer algunas cosas, a saber:

1. La feria artesanal que se instalaba hace algunas décadas por 15 días en primavera frente a la Facultad de Derecho de la Universidad de Chile, fue autorizada en forma permanente sobre el parque. Esto significa que está instalada sobre un Bien Nacional de Uso Público, y por tanto, no corresponde hablar de "terrenos de la feria artesanal".

\footnotetext{
${ }^{5}$ EL MERCURIO de Santiago, "Terrenos de feria artesanal", recuadro de: "Megaproyecto en Pío Nono esquina de Bellavista: desde departamentos hasta cine", PROPIEDADES, domingo 17 de junio de 2007.
} 


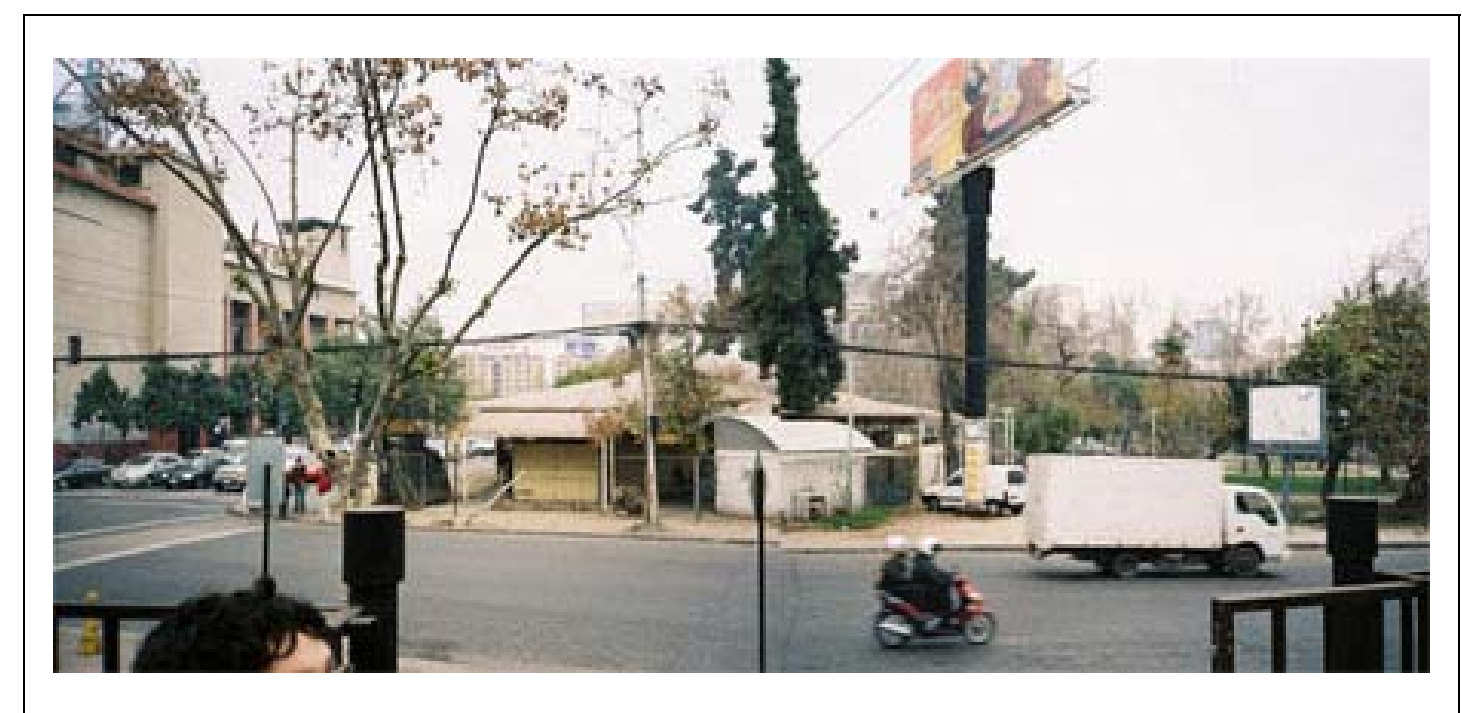

Fig.4 Imagen de feria artesanal autorizada sobre acceso principal del Parque J.D. Gómez Rojas, frente a la Facultad de Derecho de la U. de Chile, incluyendo letreros de propaganda de variados formatos.

2. El status de Bien Nacional de Uso Público le fue confirmado en el Plan Intercomunal de Santiago aprobado desde 1960, y como parte de las 690 hás ubicadas dentro de los límites urbanos de este plan, destinadas a espacios verdes y recreacionales junto al río Mapocho ("Cuenca del Río Mapocho") ${ }^{6}$.

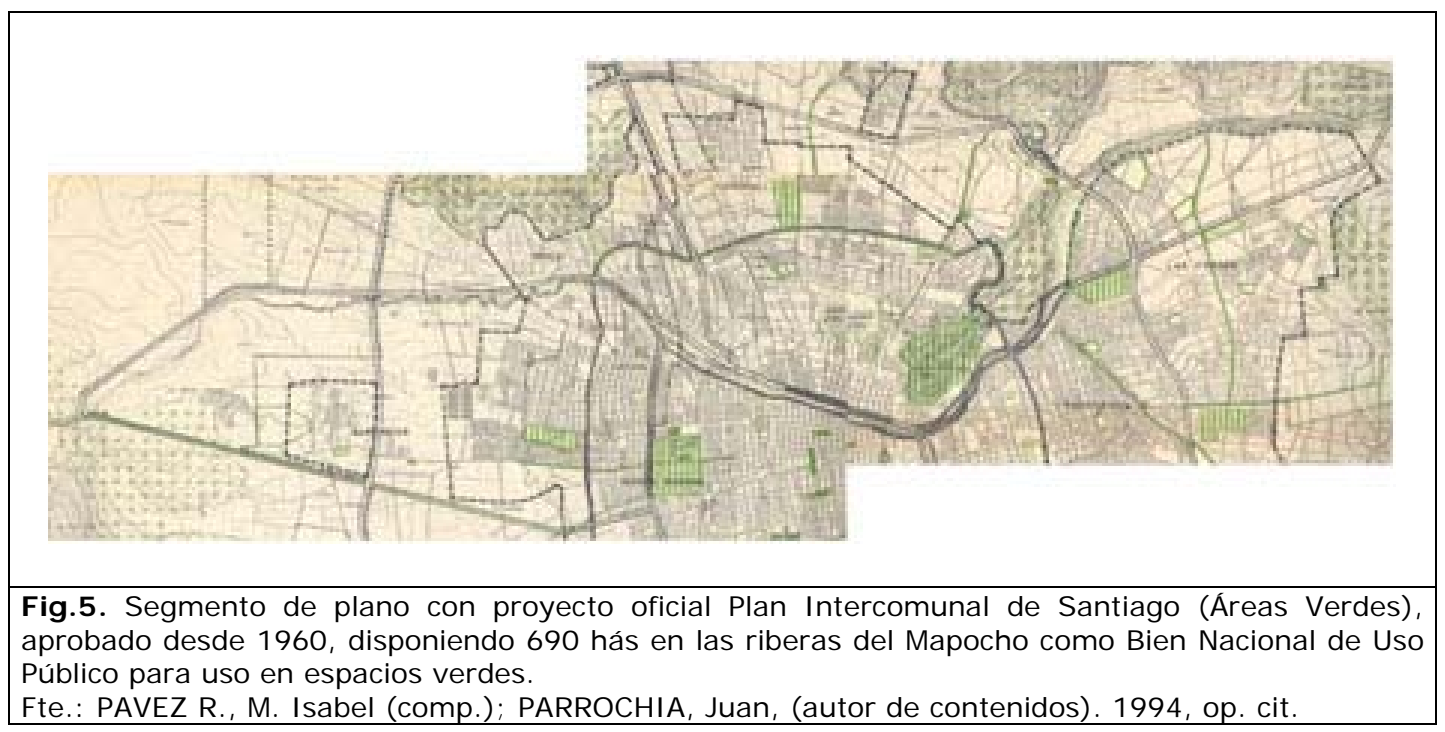

3. El espíritu de dicho Plan respecto al río Mapocho y sus riberas se asoció tempranamente -gracias a la visión de futuro de los autores Arqtos. J. Honold y J. Parrochia- a la existencia, preservación y enriquecimiento de un corredor ecológico-

\footnotetext{
${ }^{6}$ PAVEZ R., M. I sabel (comp.); PARROCHIA, Juan, (autor de contenidos). 1994. El Plan tridimensional de Ordenamiento Territorial y la Región Metropolitana de Santiago 1960-2000, D. Urbanismo, F.A.U., U. Chile, Día Mundial del Urbanismo, Santiago, noviembre de 1994, 116 págs. Ilus. Segunda edición [en línea] en Biblioteca Digital de la U. Chile, 2001.

También se dispuso en la ocasión 30 hás frente a Puente Alto, Cuenca del río Maipo, con el mismo estatus de Bien nacional de Uso público.
} 
paisajístico, sin olvidar el potencial multifacético del río como recurso hídrico, recreacional, vial, agrícola, entre otros.

4. El parque J.D. Gómez Rojas ha constituido por muchas décadas un conjunto armónico apreciable por cualquier persona con algo de sensibilidad, -siendo parte, además, de las imágenes compartidas por todos los habitantes de Santiago-, con los siguientes espacios y edificios:

a) el río Mapocho,

b) el Parque Forestal, en la ladera opuesta del Mapocho,

c) la Facultad de Derecho de la Universidad de Chile, obra señera del Arquitecto Premio Nacional de Arquitectura, Juan Martínez Gutiérrez,

d) la iglesia del Colegio Alemán, edificio protegido,

e) el espacio mayor de la plaza Baquedano-Italia,

f) el cerro Parque San Cristóbal.

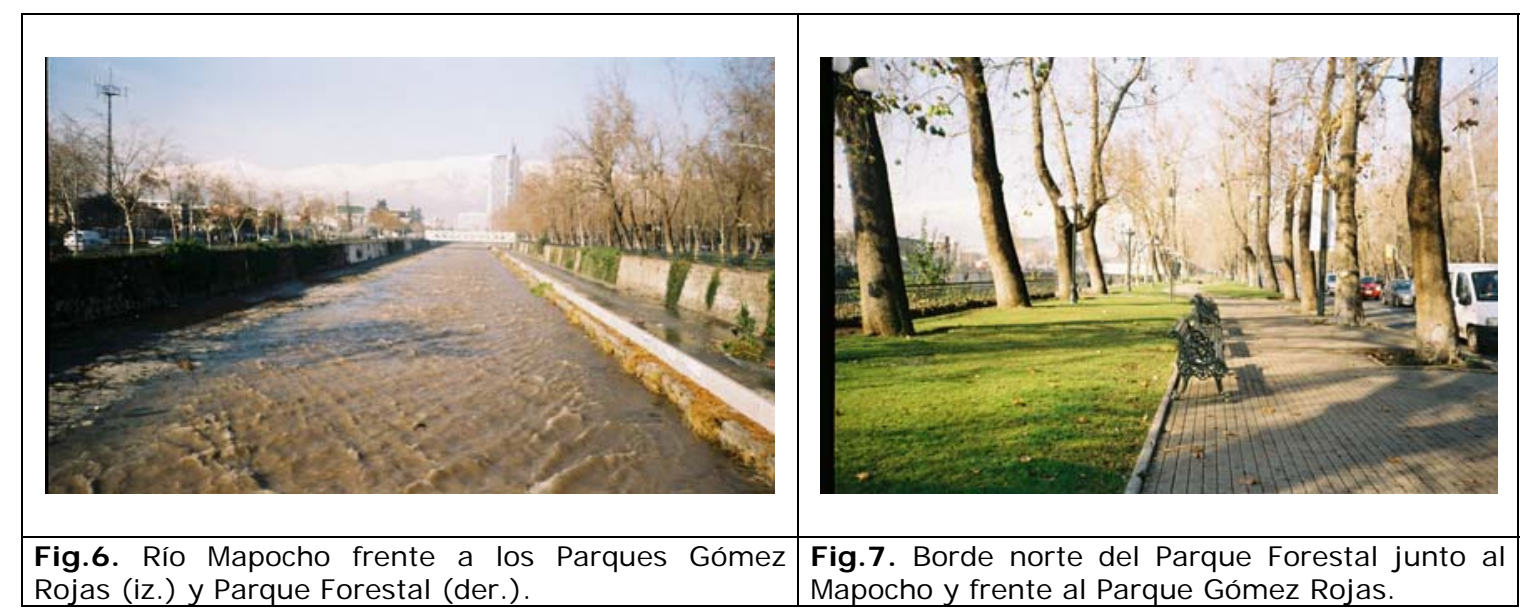

\begin{tabular}{|l|l|l|l|}
\hline &
\end{tabular}




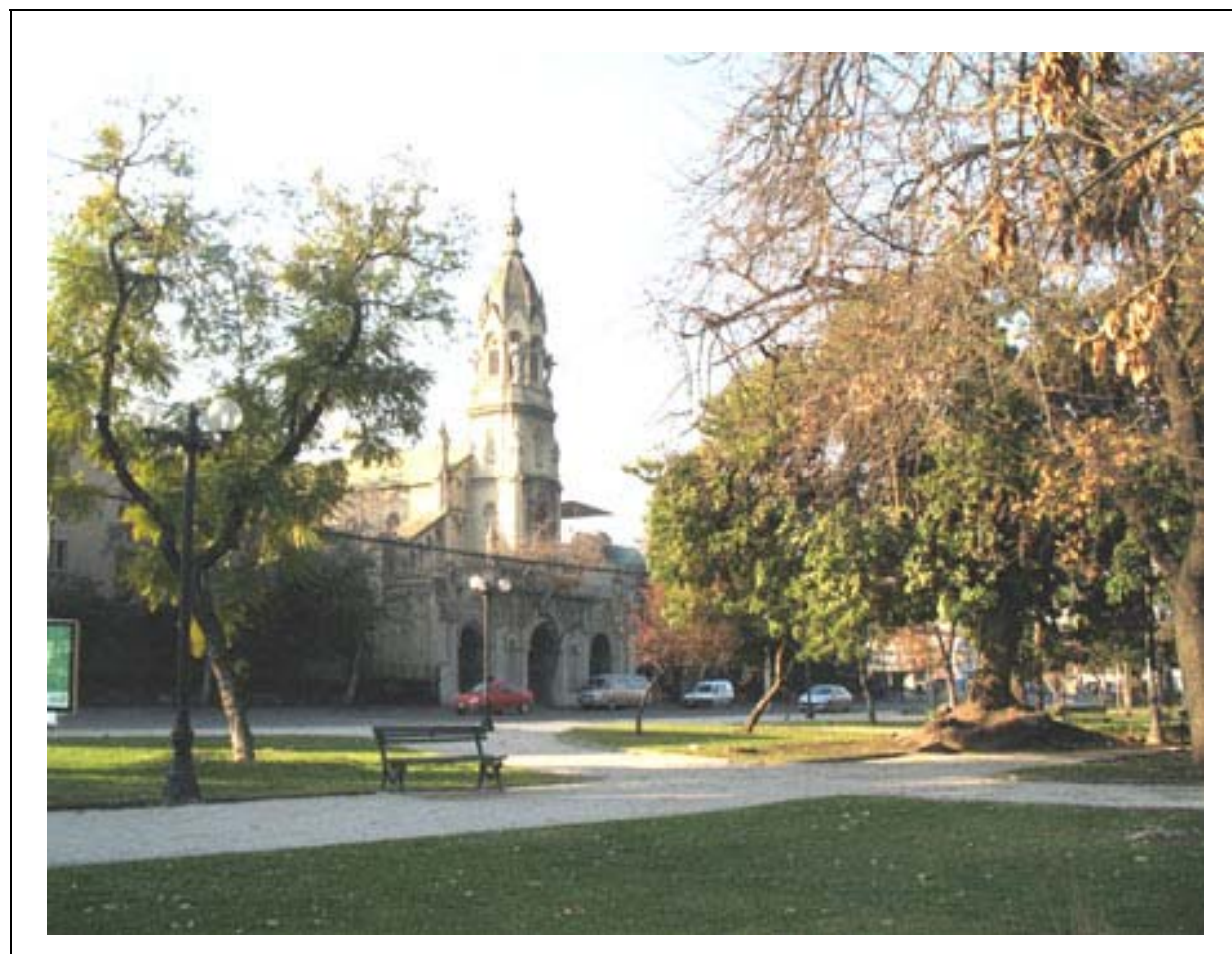

Fig. 10. Iglesia del antiguo Liceo Alemán, ubicada aproximadamente sobre el eje de simetría norte-sur del tramo practicable del Parque Gómez Rojas.

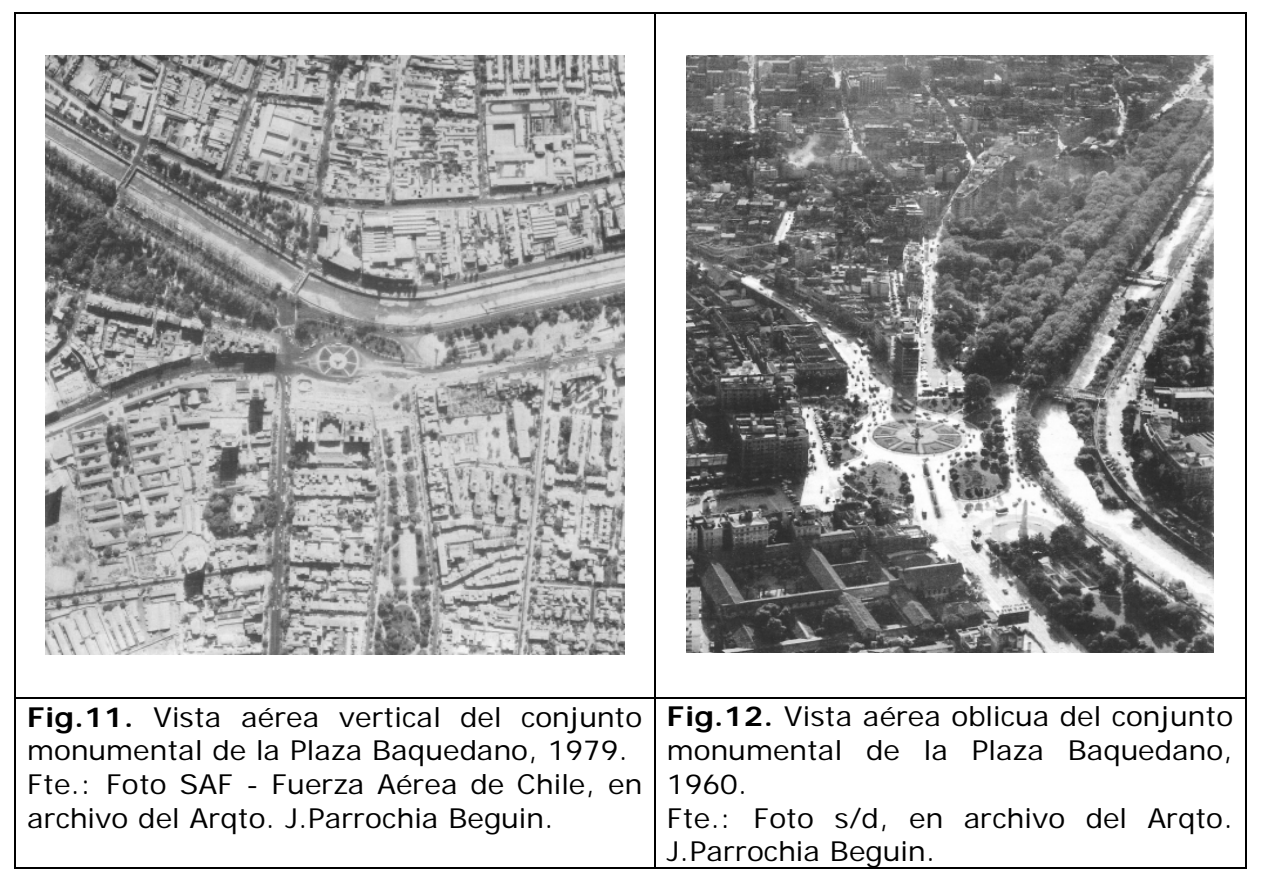

5. Adicionalmente, el Parque Gómez Rojas forma hoy parte de uno de los proyectos del Bicentenario, el llamado "Anillo Interior de Santiago", el cual busca generar las condiciones para transformar áreas edificadas deterioradas del centro y pericentro de la capital, aportando una mejor y mayor dotación de espacios verdes, una mejor 
conectividad, más servicios, en suma, un mayor grado de urbanidad en estos espacios ${ }^{7}$.

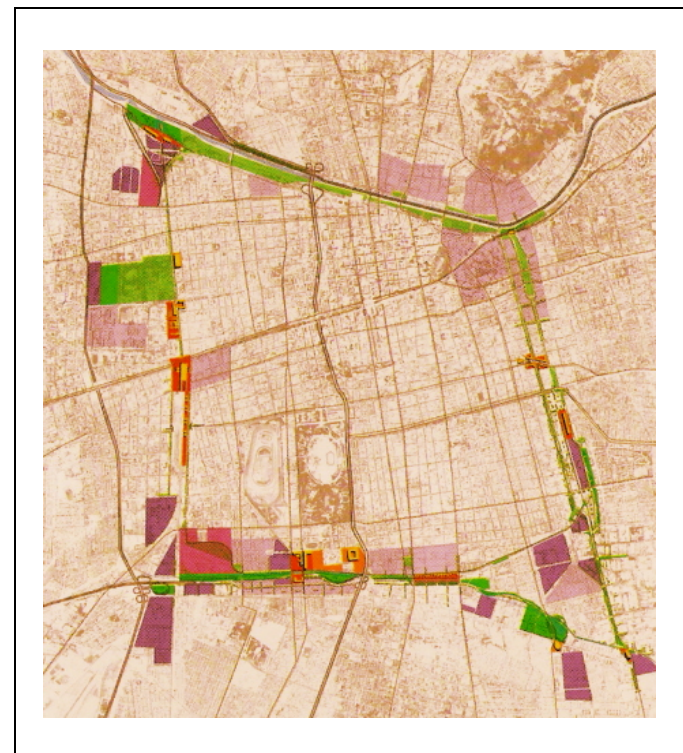

Fig.13. El "Anillo Interior de Santiago", incluyendo el Parque J.D. Gómez Rojas, entre puentes Loreto y Pío Nono, proyecto del Bicentenario.

Fte.: SERRANO M., Verónica, 2003.

"Proyectos Bicentenario", en: revista CA -

Ciudad y Arquitectura №112, pp.30-31.

\section{Acciones negativas}

Desde hace algún tiempo observamos en diversas partes de la ciudad, una especie de estrategia al entregar a ciertos usos privados los espacios públicos -como es el caso de la feria artesanal en sitio, y la instalación de propaganda en letreros en gran densidad y todos los formatos- generándose, así, un severo deterioro paisajístico y una paulatina desaparición de las especies vegetales.

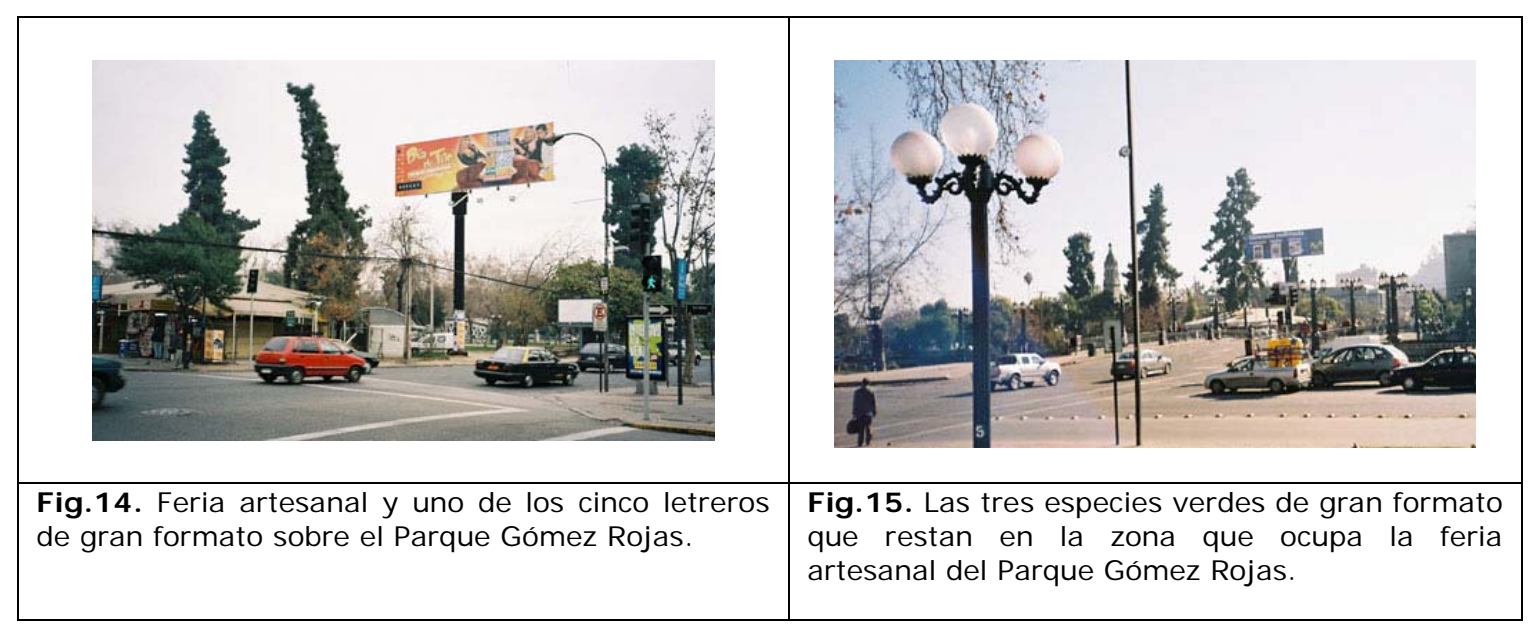

7 SERRANO M., Verónica, 2003. “Proyectos Bicentenario”, en: revista CA - Ciudad y Arquitectura №112, pp.30-31. 


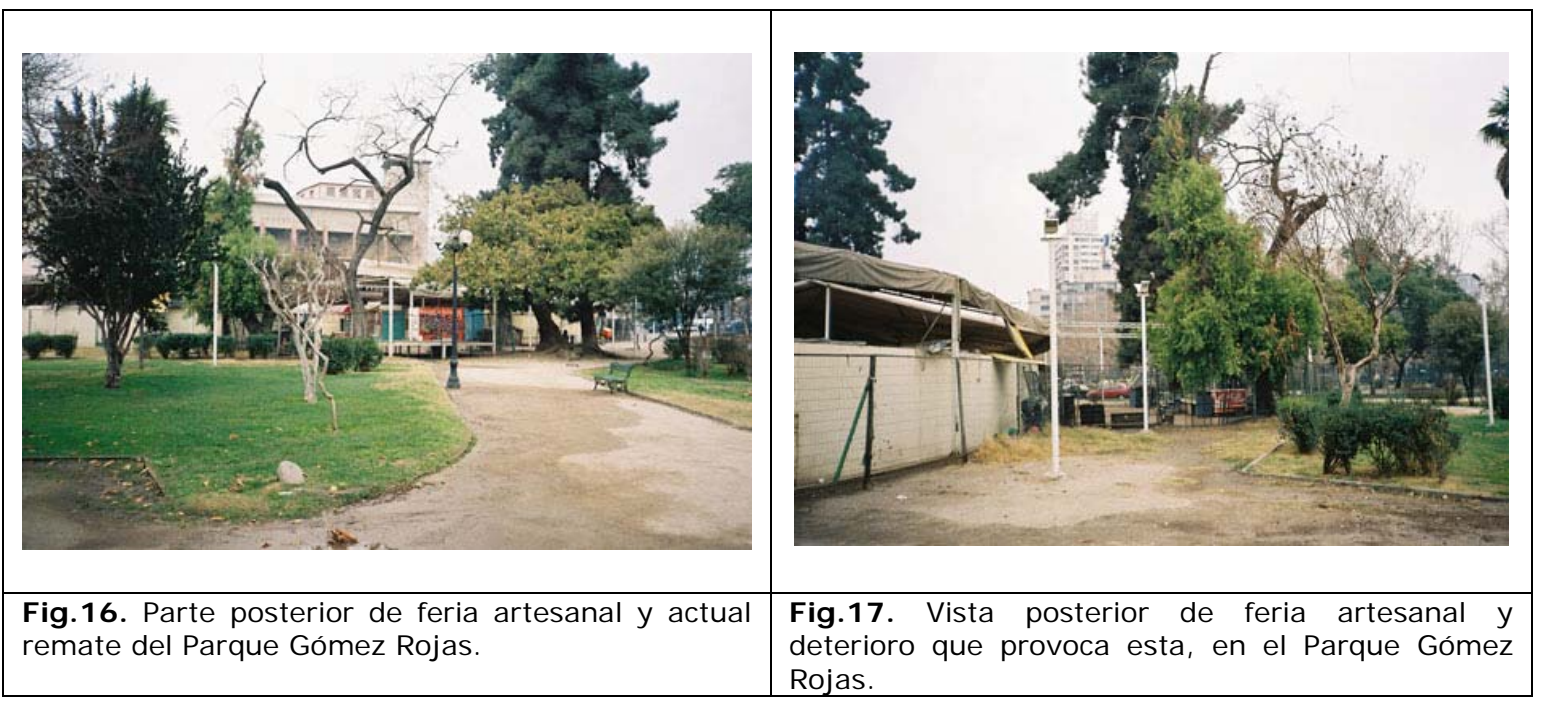

Se da paso luego a intervenciones rentables -toda vez que están sobre bienes públicos- que terminan de desvirtuarlos y que son presentados como proyectos "espectaculares". Es lamentable que cada día retrocedamos en materia de urbanismo, urbanidad, civilidad y calidad de vida, y que las diversas autoridades encargadas de proteger los parques bienes nacionales de uso público no estén cumpliendo su papel.

\section{Conclusiones}

Pensamos que tanto por las razones antes expuestas, como por el hecho de estarse densificando en población residencial y en edificación el frente norte de Bellavista, y más temprano que tarde, el interior de este barrio - lo que traerá como consecuencia necesidades mayores de espacios verdes practicables por todos los grupos etarios-, la única intervención posible en el espacio del Parque Gómez Rojas es su restauración como tal. Debe recordarse que los estándares de superficie de espacios verdes por persona son hoy en Santiago muy inferiores a lo deseable.

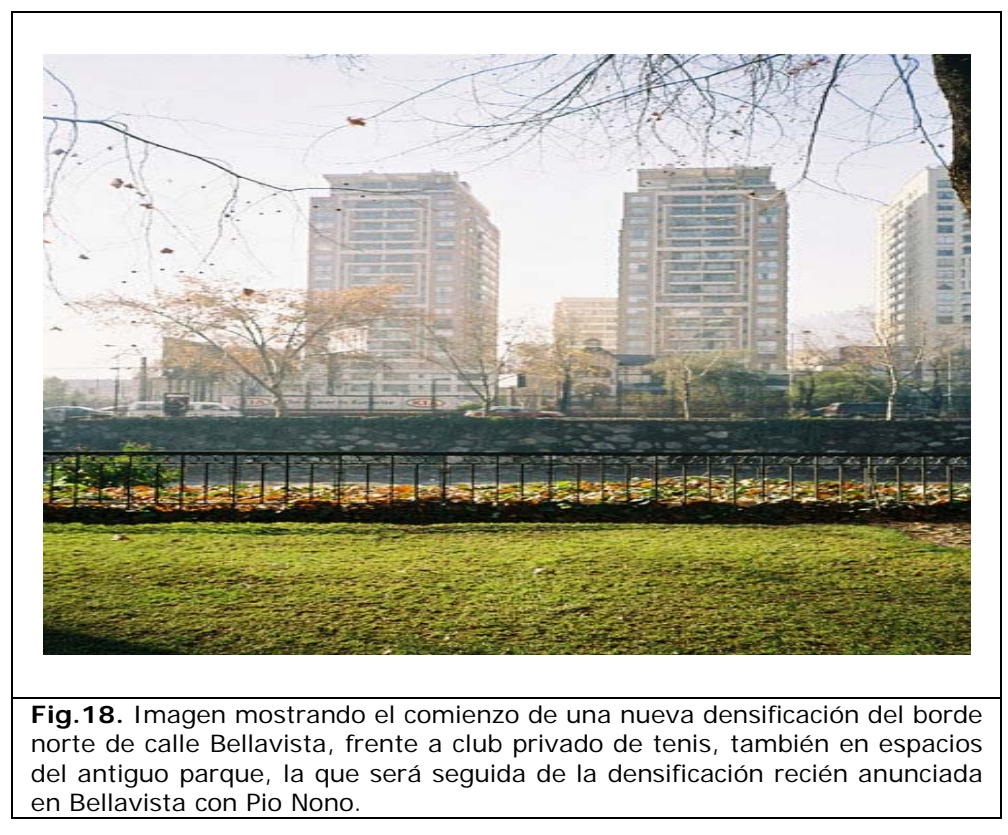


Queda en evidencia, además, la necesidad de activar la asociatividad positiva de los municipios que contienen diversas partes del espacio mayor de la plaza Baquedano y su entorno, para el mantenimiento y mejoramiento de sus diversos espacios públicos y la preservación de los edificios valiosos en coordinación.

Por último, es necesario a las autoridades locales, tomar conciencia que la renovación y densificación de los barrios residenciales en sus comunas debe integrarse a los corredores ecológicos mayores existentes, y no contribuir a la disminución de su superficie, a su deterioro e incluso a su paulatina desaparición.

\section{Bibliografía}

-ALLARD, Pablo y GUTIÉRREZ, Alejandro. "Dongtan:abriendo la huella ecológica". En: FOCO 76 ideas de ciudad N4, 2007, pp. 27-31.

-ALBURQUERQUE FUSCHINI, Germán, 1999. "Gómez Rojas, el Cristo de los poetas". En: REVISTA DERECHO Y HUMANIDADES №7, Facultad de Derecho de la Universidad de Chile, pp.153-168. [Capítulo de tesis para optar a Licenciatura en Historia, P. U. Católica de Chile, 1997].

-BOLOÑA, Nicanor (Cartógrafo), s/f. "Plano jeneral de la ciudad de Santiago e inmediaciones", escala original 1:8.500, 4aㅡ edición, c. 1912.

-EL MERCURIO de Santiago, "Terrenos de feria artesanal", recuadro de: "Megaproyecto en Pío Nono esquina de Bellavista: desde departamentos hasta cine", sección PROPIEDADES, domingo 17 de junio de 2007.

-LEHMANN DE IZQUIERDO, Antonia y MÉNDEZ B., Ramón Alfonso. La ciudad y sus arquitectos. Concurso de Anteproyectos Plaza Baquedano, Santiago de Chile, Ed. Universitaria S.A., 1982, 76 págs.

PAVEZ R., M. Isabel: "Identidad, ordenamiento territorial y oportunidades: espacios públicos y recreación para la Región Metropolitana de Santiago Siglo XXI", En: REVISTA DE URBANISMO, digital, $N^{\circ} 14$, D. Urbanismo F.A.U. U. de Chile, Primer semestre 2006, 21 págs. ilustradas.

-PAVEZ R., M.Isabel, “Espacios Públicos: Un proceso de deconstructivismo contra ciudadano", Santiago, En REVISTA DERECHO Y HUMANIDADES N8 (Número Especial Desplazamientos Privado-Público), ISBN 956-19-0348-2, FACULTAD DE DERECHO de la Universidad de Chile, 2000-2001, pp. 279-305, ilustrado.

-PARROCHIA B., Juan. 1980. Santiago en el tercer cuarto del siglo XX: El transporte metropolitano en Chile, realizaciones de Metro y Vialidad Urbana, Edición del Departamento de Planificación Urbano - Regional, Facultad de Arquitectura y Urbanismo de la Universidad de Chile, Santiago, 1980, 237 págs. ilustradas.

-PAVEZ R., M. Isabel (comp.); PARROCHIA, Juan, (autor de contenidos). 1994. El Plan tridimensional de Ordenamiento Territorial y la Región Metropolitana de Santiago 1960-2000, D. Urbanismo, F.A.U., U. Chile, Día Mundial del Urbanismo, Santiago, noviembre de 1994, 116 págs. Ilus. Segunda edición [en línea] en Biblioteca Digital de la U. Chile, 2001. 
-SERRANO M., Verónica, 2003. "Proyectos Bicentenario", en: revista CA - Ciudad y Arquitectura №112, pp.30-31.

Fotografías: 4, 6,7,14,15,16,17,18, M.I.Pavez; 2, 10, Diego Vallejos O. ()

M.I.Pavez es Arqta. U. de Chile, DEA en Urbanismo por la Universidad de París, Doctora en Arquitectura y Urbanismo por la U. Politécnica de Madrid, y académica del Departamento de Urbanismo de la F.A.U. de la U. de Chile.

<mpavez@uchile.cl> 